\title{
POLÍTICAS PÚBLICAS E POLÍTICAS EDUCACIONAIS: PERCURSOS HISTÓRICOS, INTERFACES E CONTRADIÇÕES DAS PRODUÇÕES NA DÉCADA DE 2000 ${ }^{1}$
}

\author{
Antonia Almeida Silva ${ }^{2}$ \\ UEFS \\ Elisângela Alves da Silva Scaff ${ }^{3}$ \\ UFGD \\ Márcia Aparecida Jacomini ${ }^{4}$ \\ UNIFESP
}

RESUMO

Este estudo está voltado à apreensão de possíveis mudanças na tradição metodológica da área de Políticas Educacionais, confrontando os elementos constitutivos da produção difundida pela Associação Nacional de Pós-Graduação e Pesquisa em Educação (Anped), no Grupo de Trabalho Estado e Política Educacional, entre 2000 e 2010, com os que sobressaíram em estudos anteriores. O trabalho teve como base empírica todos os resumos das comunicações aprovadas pela Anped no período e os textos integrais que focalizaram questões teórico-metodológicas no campo das Políticas Educacionais. Evidenciou-se a abundância de produções individuais e a escassez de investigações mais atentas aos desafios de constituição do campo. Entre as contribuições desta pesquisa, problematizamse os usos e sentidos da categoria Estado e defende-se sua centralidade como chave explicativa do campo.

Palavras-chave: Políticas educacionais; Estado. Políticas públicas; Campo.

\section{PUBLIC POLICIES AND EDUCATIONAL POLICY: HISTORICAL PATHWAYS, INTERFACES AND CONTRADICTIONS OF THE PRODUCTIONS IN DECADE OF 2000}

\begin{abstract}
This study is focused on the apprehension of possible changes in the methodological tradition of the area of Educational Policy, comparing the elements of production disseminated by the Associação Nacional de Pós-Graduação e Pesquisa em Educação (Anped), in the Working Group State and Education Policy between 2000 and 2010, with those highlighted in previous studies. The work had as empirical base all the abstracts of the communications approved by Anped in the period, and the full texts that focused theoretical and methodological issues in the field of the Educational Policies. It was evident abundance of individual productions and shortage of researches more careful to the challenges of the formation of this field. Among the contributions of this research, it was discussed the uses and meanings of the category State and it was defended its centrality as an explanatory key of the field.
\end{abstract}

Keywords: Educational policies; State. Public; policy; Field. 


\section{Introdução}

A projeção da produção acadêmica em Políticas Públicas vem sendo notada no Brasil desde o final da década de 1990, simultânea à acentuação das fragilidades que circunscrevem a consolidação dessa área de conhecimento. Acompanhando esse debate, o presente estudo problematiza as características da produção apresentada no Grupo de Trabalho Estado e Política Educacional (GT05) da Associação Nacional de Pós-Graduação e Pesquisa em Educação (Anped) no período 2000-2010. Em diálogo com a premissa de que a área carrega uma tradição metodológica de temas e de teorias difusas (SOUZA, 2003a), o texto se volta para a apreensão de possíveis mudanças dessas características, confrontando os elementos constitutivos dos trabalhos mais recentes do GT com os que sobressaíram em estudos anteriores. É o caso do artigo publicado por Azevedo e Aguiar (2001b), resultante de pesquisa sobre os trabalhos apresentados no mesmo GT, no período de 1993 a 2000. Nesse texto, as autoras levantaram as tendências da produção do conhecimento sobre a política educacional no Brasil e destacaram alguns desafios a serem suplantados para a consolidação desse campo, o que nos instigou a retornar ao tema e verificar as possíveis mudanças nas características dos trabalhos da área, confrontando-as com o debate mais amplo sobre a produção em políticas públicas na década de 2000.

Assim, tomando o total das comunicações aprovadas no âmbito do GT05 no período 2000-2010, o trabalho empreendido aqui assumiu como base empírica todos os resumos veiculados nos cadernos publicados pela Anped nas 11 reuniões da entidade no período, além da análise integral das comunicações que se voltaram para questões teóricometodológicas na área, as quais representaram 5\% dos trabalhos apresentados pelo GT nesse mesmo espaço. O texto está estruturado em três eixos. O primeiro trata do campo das Políticas Públicas e das Políticas Educacionais, a partir do conceito de campo de Bourdieu (2010). O segundo discute o estado do conhecimento em política educacional por meio do diálogo entre os dados desta pesquisa e a produção da área. O terceiro eixo problematiza as relações entre Estado e políticas públicas, assumindo que elas são resultado dos embates das distintas forças que atuam tanto na sociedade civil quanto na sociedade política e representam projetos de sociedade em disputa.

\section{Políticas públicas e políticas educacionais: percursos históricos e interfaces}

Em Bourdieu (2010), o conceito de campo designa as referências dos espaços ocupados pelos agentes sociais a partir do princípio da diferenciação. Espaços de relações sociais são, neste ângulo, espaços de defesa de interesses de grupos sociais. O campo aqui é entendido como um espaço de disputa de agentes mobilizados pela propriedade de recursos materiais e simbólicos. Adverte o autor, contudo, que:

Esta estrutura não é imutável e a topologia que descreve um estado de posições sociais permite fundar uma análise dinâmica da conservação e da transformação da estrutura da distribuição das propriedades ativas e, assim, do espaço social. É isto que acredito expressar quando descrevo o espaço social global como um campo, isto é, ao mesmo tempo, como um campo de forças, cuja necessidade se impõe aos agentes que nele se encontram envolvidos, e como um campo de lutas, no interior do qual os agentes se enfrentam, com meios e fins diferenciados conforme sua posição na estrutura do campo de forças, contribuindo assim para a 
conservação ou a transformação de sua estrutura. (BOURDIEU, 2010, p. 50 , grifo do autor)

Em relação direta com o conceito de campo de Bourdieu (2010), assumimos neste estudo que o debate sobre a constituição das políticas públicas e das políticas educacionais como um campo de conhecimento passa pela construção do seu reconhecimento como tal, isto é, a concentração de capitais acadêmicos que respaldem os enfrentamentos dos agentes sociais nele implicados. O campo aqui encerra tanto a defesa de interesses de grupos sociais em seus aspectos diferenciais quanto o movimento de constituição de um espaço de afirmação disciplinar. Em nossa compreensão, essa dupla dimensão, de natureza não excludente, marca a trajetória das produções em políticas públicas e políticas educacionais das duas últimas décadas. Situadas como um ramo da Ciência Política, as políticas públicas não são objeto exclusivo dessa área, mas de várias disciplinas como a Sociologia, a Economia, a Psicologia e, em nosso julgamento, a Pedagogia, sempre ausente no rol das áreas de conhecimento que problematizam as políticas públicas na literatura não especializada. Todavia, o estudo em políticas públicas como uma unidade de análise ou uma área de conhecimento ainda é relativamente recente no Brasil, sendo notado em alguns estudos como uma área em construção, o que indica a necessidade de investimentos acadêmicos que colaborem para sua consolidação, conforme preconizado por Azevedo (1997), Azevedo e Aguiar (2001a, 2001b), Melo (1999) e Souza (2003a, 2003b).

A retomada histórica da produção na área faz notar que, tanto em Ciências Sociais quanto em Educação, a agenda de intensificação de estudos em políticas públicas é situada a partir da década de 1980, em concomitância com o fim da ditadura civil-militar instaurada no Brasil em 1964 (AZEVEDO, 1997). Além de relativamente recente, Melo (1999, p. 65) observa que, por algum tempo, essa área de estudos conservou alguns aspectos comuns à trajetória europeia, "no sentido de que as ciências sociais distanciaramse da gestão de governo e que a análise de políticas esteve associada a entidades governamentais". E cita:

Este é o caso da Fundação para o Desenvolvimento Administrativo (Fundap), em São Paulo, e do Instituto de Pesquisa Econômica Aplicada (Ipea), do Ministério do Planejamento, criado em 1965, e que passou a desenvolver pesquisas na área, sobretudo nos anos [19]80. O Ipea edita, desde 1989, uma das revistas de maior visibilidade na área, e para a qual contribuem cientistas sociais de diversas formações, Planejamento e Políticas Públicas. (MELO, 1999, p. 65)

No contexto da pesquisa universitária, Melo (1999) ressalta como passos importantes para a institucionalização da área no Brasil a criação do Núcleo de Estudos de Políticas Públicas da Universidade Estadual de Campinas (Nepp/Unicamp), em 1984, e do GT de Políticas Públicas, no âmbito da Associação Brasileira de Pós-Graduação e Pesquisa em Ciências Sociais (Anpocs), em 1983.

Olhando para esse processo no campo educacional, verifica-se que o período de intensificação de debates e organização institucional é o mesmo. Artigo publicado por Azevedo e Aguiar (2001b) relata que, na Anped, essa área de investigação começou a ser delineada no início da década de 1980, dentro do processo de reorganização da entidade, que buscava estabelecer novas diretrizes de ação e autonomia frente ao Estado. 
Essa redefinição, dentre outras coisas, objetivou tornar a Anped mais autônoma em relação ao Estado, tendo em vista que a sua criação, nos anos [19]70, atendera a uma sugestão dos órgãos governamentais, levando-a a se caracterizar, principalmente, como um fórum de discussão dos Programas de Pós-Graduação, e a que só tangencialmente se ocupasse da pesquisa. (AZEVEDO; AGUIAR, 2001b, p. 53)

Assim, embora em 1981 a Anped passasse a operar uma ruptura com sua gênese de instituição tutelada pelo Estado, só em 1986 o GT se efetivaria, sob o nome de Grupo de Trabalho sobre Política, Administração e Planejamento da Educação, vindo dois anos depois a ser nomeado Estado e Política Educacional no Brasil e, por fim, em 1995, Estado e Política Educacional (AZEVEDO, AGUIAR, 2001b), como é identificado até a presente data.

À semelhança de outras entidades da sociedade civil, também a Anpae passaria a assumir o enfoque das políticas públicas mais recentemente. Criada em 1962, sob a denominação de Associação Nacional de Professores de Administração Escolar, a Anpae protagonizou uma longa história na organização de profissionais da Educação, desde os seus primórdios, problematizando a administração da educação. Passou por mudanças em seu nome por quatro vezes, sendo a última em 1996, quando pela primeira vez incorporou à sua denominação o termo "política", passando a ser chamada de Associação Nacional de Política e Administração da Educação (SANDER, 2007, p. 437).

Dados como estes confirmam que a década de 1990 constituiu-se em um período de intensificação dos estudos com foco nas políticas públicas, expresso tanto na produção de estados da arte, na organização e publicização de dossiês temáticos, bem como na organização de eventos pautando temáticas ligadas à área. Como parte desse processo, dois dossiês publicados em 2003 enfatizaram o crescimento da importância de estudos dessa natureza, ressaltando alguns desafios a serem contornados para a consolidação da investigação em política pública no Brasil. O primeiro dossiê, publicado na Revista Brasileira de Ciências Sociais (2003), reuniu quatro artigos sobre o tema, e o segundo, publicado no Caderno CRH (2003), reuniu mais sete artigos. Antes disso, em trabalho publicado pela Anpocs com apoio da Coordenação de Aperfeiçoamento de Pessoal de Nível Superior (Capes), Melo (1999) já discutia a produção intelectual brasileira em políticas públicas.

Em relação à política educacional, uma contribuição a ser ressaltada no debate sobre a construção da área foi a publicação do estado da arte em política educacional (WITTMANN, GRACINDO, 2001), uma iniciativa da Anpae que reuniu vários pesquisadores, oferecendo, além de uma rigorosa análise sobre as produções e seus vários enfoques, pistas para novas investigações.

Ainda na década de 1990, Azevedo (1997) apresentou importante trabalho, situando a educação como política pública e explorando as abordagens que vêm orientando a produção na área, inclusive defendendo a opção analítica sugerida por Muller e Jobert. Segundo Azevedo (1997), esses autores

Preocupam-se com a íntima e dialética relação entre a intervenção estatal e a estrutura da organização social. Enfatizam, assim, a amplitude do espaço "político" das políticas públicas, prefigurando-o na dialética da relação entre reprodução global das sociedades e a reprodução de cada setor específico para o qual se concebe e implementa determinada política. (AZEVEDO, 1997, p. 58) 
Com esta análise, Azevedo (1997) não só dá conta dos desafios para a consolidação da área na dimensão teórico-analítica, mas também sinaliza sua diversidade e a tendência a um alinhamento teórico-metodológico que passa a buscar referenciais mais heterodoxos, como os advogados nessa obra.

Nos anos 2000, uma relevante contribuição para a organização da produção acadêmica na área foi dada por Souza e Faria (2005), cuja obra apresenta bibliografia analítica da produção sobre política, gestão e financiamento de sistemas municipais públicos de Educação no Brasil no período de 1996 a 2005. Contemplando artigos em periódicos, livros, capítulos, dissertações, teses e trabalhos em anais de eventos científicos produzidos em nível nacional, os autores catalogaram 355 referências, realizando minuciosa análise das tendências de produção na área no período citado.

É comum a todas as produções que tomaram as políticas públicas como objeto, inclusive as voltadas para a Educação, a análise da recente estruturação da área, bem como a avaliação de que esta ainda demanda atenção quanto às abordagens teóricas e às metodologias de pesquisa. Entre os obstáculos a serem vencidos, são citados: escassa acumulação de conhecimento, abundância de estudos setoriais sem a verticalização desejada, contiguidade da produção aos órgãos governamentais e reduzido número de redes de produções entre pesquisadores. A análise das produções que circularam no GT Estado e Política Educacional da Anped no período 2000-2010 nos faz verificar que os obstáculos referidos também povoam a área de Políticas Educacionais. Vejamos!

\section{Características da produção do GT Estado e Política Educacional (2000-2010)}

Tomando o conjunto dos trabalhos aprovados pelo GT05 no período em tela, a análise das tendências da produção do conhecimento sobre a política educacional foi pautada pela caracterização da produção segundo seis critérios gerais: número de trabalhos aprovados pelo GT; origem regional dos trabalhos apresentados; origem institucional; natureza das instituições; condições materiais para a realização da pesquisa quanto a financiamento; e, por fim, os eixos temáticos dos trabalhos. Tais eixos resultaram numa segunda ordem de classificação dos trabalhos em 11 categorias, a saber: 1) Planejamento, avaliação e qualidade da educação; 2) Gestão da educação e descentralização; 3) Estado e reformas educacionais; 4) Estado, direito à educação e terceiro setor; 5) Formação de professores, carreira e remuneração; 6) Financiamento e controle social; 7) Abordagens teórico-metodológicas em políticas públicas; 8) Educação permanente e educação superior; 9) Programas de assistência ao estudante; 10) Ensino médio e educação profissional; 11) Políticas afirmativas e cotas. Estas categorias foram estabelecidas em observância às classificações realizadas pelo GT05 em algumas reuniões do período em tela, embora com ajustes e alterações para contemplar a diversidade de temas.

A classificação dos trabalhos nessas categorias teve como base a análise de conteúdo dos resumos e das comunicações selecionadas, buscando identificar, primeiro, os elementos de diferenciação dos 203 trabalhos aprovados pelo GT05, e depois, o agrupamento dos textos a partir de eixos temáticos análogos. Como estabelece Bardin (2004, p. 111):

A categorização é uma operação de classificação de elementos constitutivos de um conjunto, por diferenciação e, seguidamente, por 
reagrupamento segundo o gênero (analogia), com os critérios previamente definidos. As categorias são rubricas ou classes, que reúnem um grupo de elementos (unidades de registro, no caso da análise de conteúdo) sob um título genérico, agrupamento esse efetuado em razão dos caracteres comuns destes elementos.

Após a análise de conteúdo de todos os resumos e a respectiva classificação, todos os textos situados na categoria "Abordagens teórico-metodológicas em políticas públicas" foram analisados na íntegra, visando a apreender se e como essa produção dialogou com a bibliografia selecionada que problematiza o estado do conhecimento em políticas públicas, particularmente no que se refere à educação, bem como se a produção do GT sinaliza para um estágio distinto do diagnosticado na literatura apresentada para a análise dos percursos históricos e interfaces da produção em políticas públicas e políticas educacionais. Sobre o número de trabalhos que circulou no GT05 entre 2000 e 2010, verificou-se que 203 lograram êxito no período. Desse total, apenas 122 foram incluídos na agenda dos trabalhos a serem apresentados pelos autores e os demais, embora aprovados no mérito, foram classificados como excedentes e constaram apenas nos anais das reuniões.

\section{Gráfico 1 - Trabalhos apresentados e excedentes - Anped (2000 - 2010)}

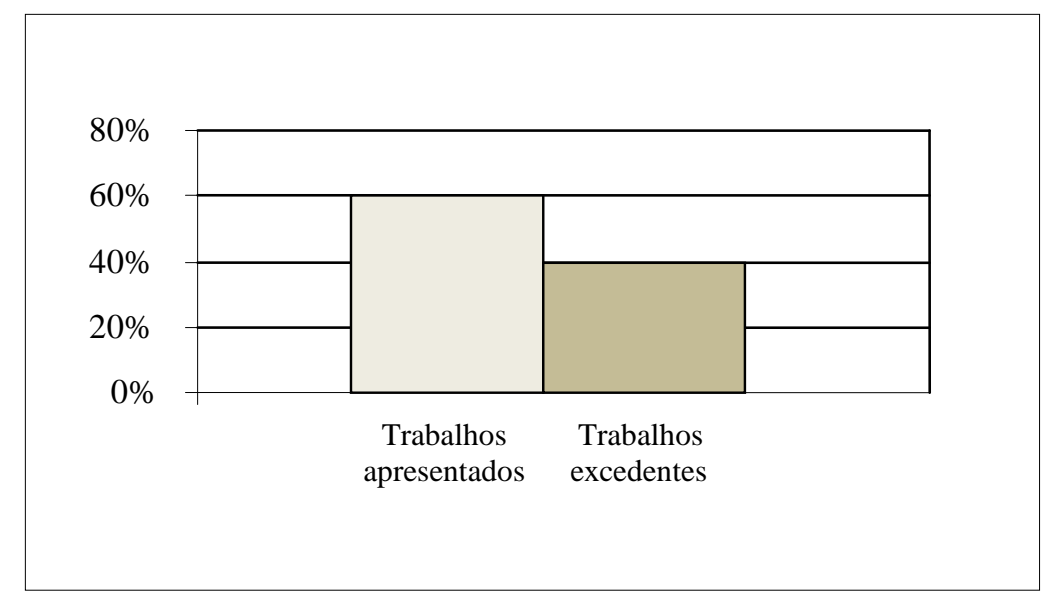

Fonte: as autoras (2016).

Como podemos acompanhar no Gráfico 1, a diferença entre o número de trabalhos publicados nos anais e o número de trabalhos incluídos na agenda do GT05 denota que a aprovação dos trabalhos no mérito vem concorrendo para a ampliação das estratégias de divulgação das produções na área, sem alterar a escala de seleção dos trabalhos proposta pela Anped.

Considerando o conjunto dos trabalhos apresentados, a Região Sudeste despontou como o principal campo de produção em política educacional, com $44 \%$ dos trabalhos apresentados no período, percentual idêntico ao número de programas de pós-graduação em Educação concentrados nessa região (44\%), segundo dados disponíveis no site da Coordenação de Aperfeiçoamento de Pessoal de Nível Superior (COORDENAÇÃO DE APERFEIÇOAMENTO DE PESSOAL DE NÍVEL SUPERIOR, 2010).

Informações desse mesmo site dão conta de que a Região Sul era a segunda do país em número de programas de pós-graduação em Educação, totalizando $28 \%$ desses programas, mais que o dobro da Região Nordeste, que possuía $11 \%$ da pós-graduação da 
área. Nesse caso, o quantitativo de trabalhos selecionados para apresentação no GT05 da Anped diferencia-se substancialmente, na medida em que a Região Nordeste aparece em segundo lugar, com $21 \%$ dos trabalhos selecionados, e a Região Sul com 15\% (ver Gráfico 2).

A Região Centro-Oeste também possuía maior número de trabalhos aprovados do que a quantidade de pós-graduações, somando $15 \%$ dos trabalhos para um percentual de $11 \%$ da pós-graduação na área. Já a Região Norte, que possuía apenas $5 \%$ dos programas de pós-graduação em Educação, teve $2 \%$ de participação no GT no período em análise.

\section{Gráfico 2 - Distribuição dos trabalhos por região geográfica - Anped (2000 - 2010)}

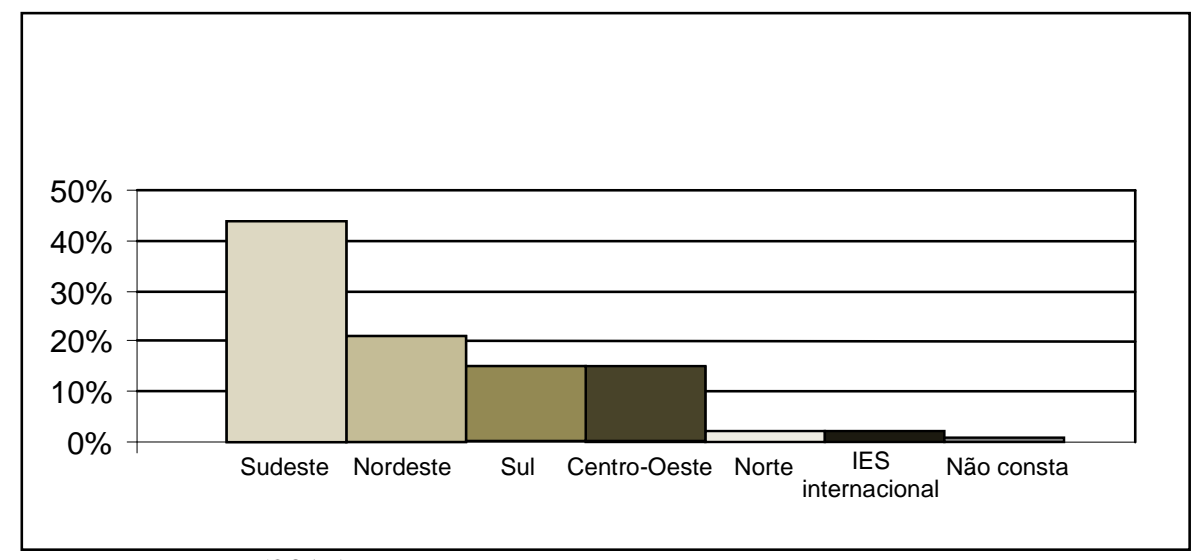

Fonte: as autoras (2016).

No tocante à origem dos autores que apresentaram trabalhos no GT, os dados retratam uma realidade já anunciada em outras pesquisas, tais como as de Ramalho e Madeira (2005) e Santos e Azevedo (2009), que indicaram a concentração de programas de pós-graduação e da produção intelectual brasileira na Região Sudeste do país.

Em relação à frequência de aprovação de trabalhos, constatou-se que a maioria dos autores teve trabalho aprovado apenas uma vez durante o período estudado: dos 187 pesquisadores cujos trabalhos foram aprovados pelo GT, $81 \%$ tiveram trabalhos aprovados uma única vez. Entre os $19 \%$ que tiveram trabalhos aprovados mais de uma vez, temos $8 \%$ duas vezes, $7 \%$ três vezes, $3 \%$ quatro vezes, $0,5 \%$ cinco e seis vezes (os dois últimos percentuais correspondem a um pesquisador em cada caso). Tais resultados evidenciam uma grande rotatividade entre os pesquisadores que apresentaram suas produções no GT, mas também mostram que há um pequeno grupo de pesquisadores no país que frequentemente submeteram e tiveram trabalhos aprovados nesse fórum. Esse dado pode indicar a consolidação de alguns pesquisadores ou grupos de pesquisa cujas produções têm-se tornado referência no campo das Políticas Públicas de Educação.

Por outro lado, percebeu-se também que a maior parte dos trabalhos apresentados é de autoria de pesquisadores com pouca visibilidade no cenário educacional brasileiro. Isto sugere que, se por um lado o GT é um espaço de apresentação de novos pesquisadores, por outro parece não privilegiar as produções de pesquisadores com carreira consolidada, exceto por meio dos trabalhos encomendados e da participação em atividades como sessões especiais e conferências.

Quanto à origem institucional dos pesquisadores, os dados sugerem que na última década o GT05 capitaneou a participação de 75 instituições de ensino superior, entre as 
quais buscamos destacar aquelas responsáveis pela aprovação mínima de quatro trabalhos, conforme o Gráfico 3, a seguir.

Gráfico 3 - Distribuição de trabalhos por IES - Anped (2000 - 2010)

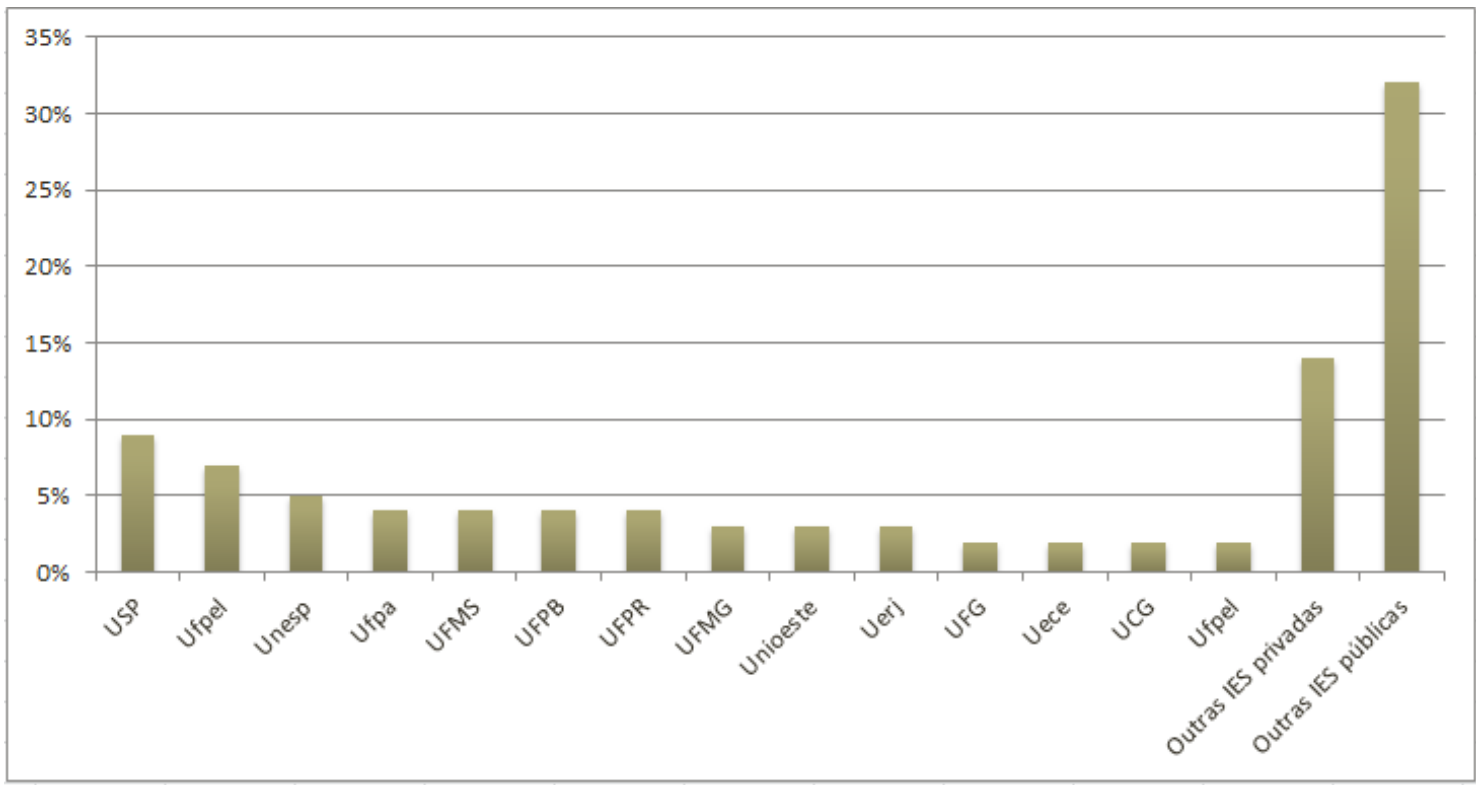

Fonte: as autoras (2016).

Não obstante a diversidade de instituições que se fizeram representar por meio de seus pesquisadores, observa-se que, dos 203 trabalhos selecionados no período, 53\% pertencem a apenas 14 instituições. Conforme os destaques do Gráfico 3, entre essas instituições, 13 são públicas e uma é privada. Considerando o conjunto dos trabalhos também se observou que $81 \%$ deles foram oriundos de instituições públicas, o que confirma a tradição de pesquisa nas universidades públicas brasileiras, principais responsáveis pela produção de conhecimento na área no país. As instituições privadas, embora em maior número no cenário nacional, apresentaram apenas 19\% das aprovações de trabalhos no GT05.

Sobre as condições materiais para a realização de pesquisas, três questões sobressaíram nos dados coletados, conforme a declaração constante nos cadernos de resumos publicados pela Anped: 1) a maior parte dos trabalhos (67\%) não recebeu financiamento ou não declarou tê-lo recebido; 2) entre os trabalhos que receberam financiamento, a Capes (10\%) e o CNPq (9\%) são responsáveis pela maioria; 3) duas agências de fomento estaduais aparecem com índices expressivos no conjunto dos trabalhos financiados: a Fundação de Amparo à Pesquisa do Estado de São Paulo (Fapesp) que financiou seis trabalhos, e a Fundação de Amparo à Pesquisa do Estado de Minas Gerais (Fapemig), com cinco trabalhos.

Disso se conclui que a maior parte das pesquisas ainda é realizada sem financiamento das agências de fomento, embora as agências federais representem, juntas, mais da metade do apoio às pesquisas ${ }^{5}$. Constatou-se, portanto, que o financiamento de pesquisa ainda foi um elemento de discriminação para a área, indicando o distanciamento das agências de fomento em relação à pesquisa em Educação. 
Gráfico 4 - Agências de fomento - 2000-2010

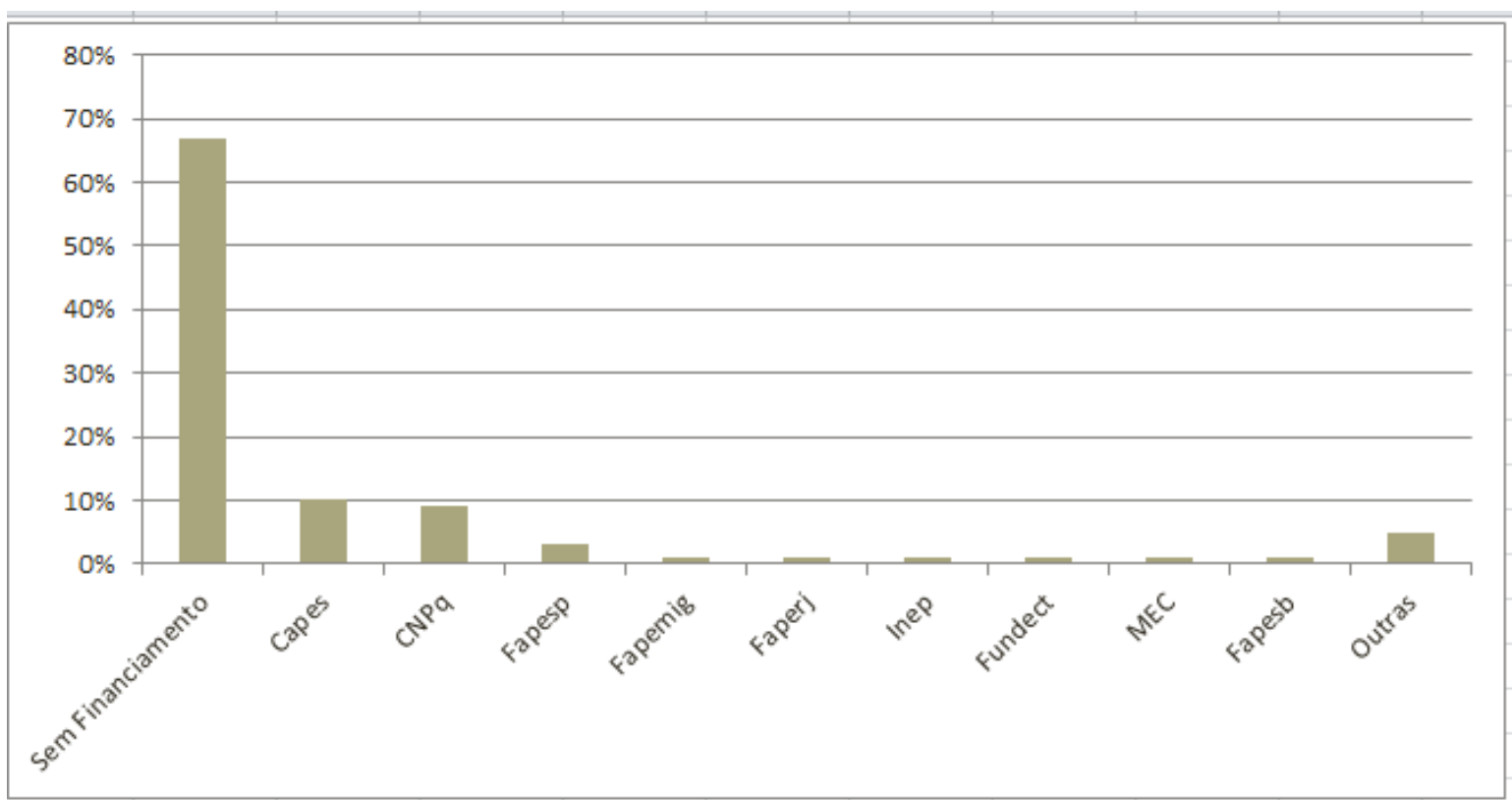

Fonte: as autoras (2016).

Quanto aos temas pesquisados, verificou-se que o GT apresentou grande diversidade, embora sobressaia o interesse pelos temas planejamento, gestão, reformas educacionais e financiamento da educação, conforme expressa o Gráfico 5.

Gráfico 5 - Frequência de temas - 2000-2010

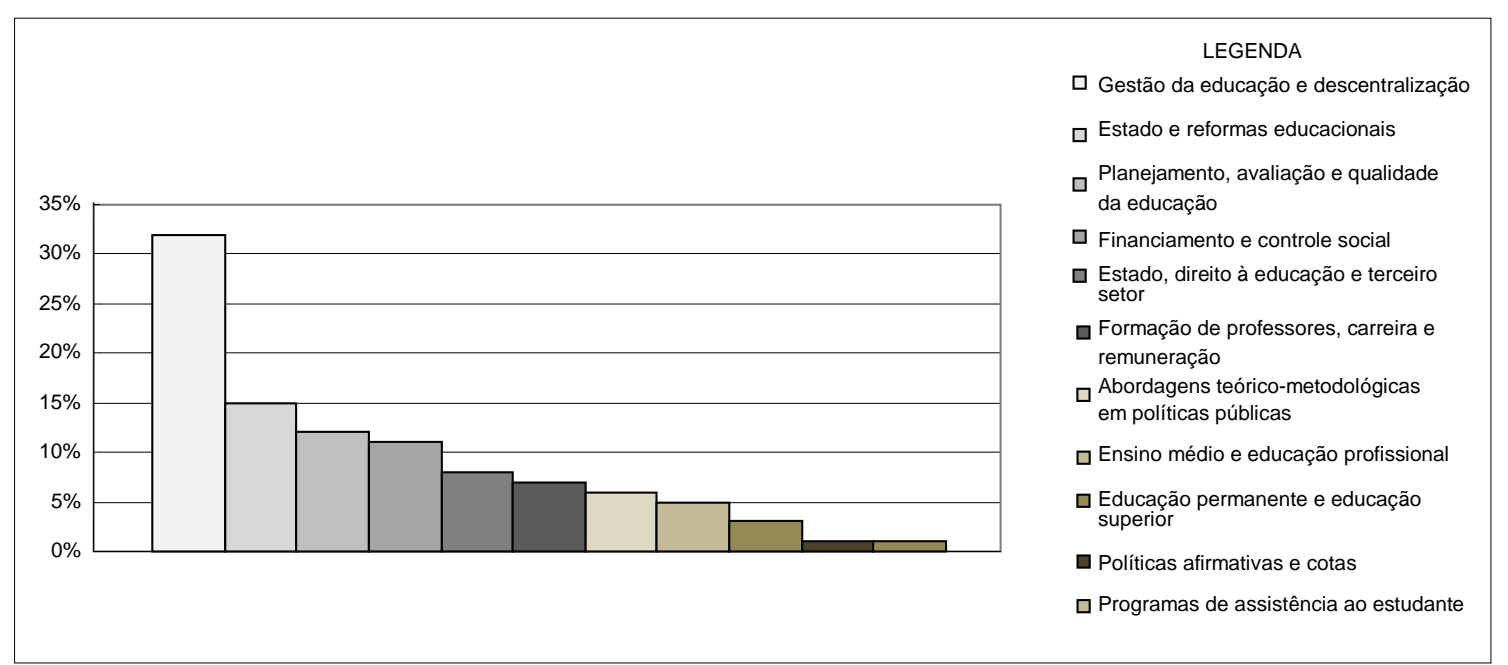

Fonte: as autoras (2016).

$\mathrm{Na}$ temática "Gestão da educação e descentralização", que angariou 32\% das comunicações aprovadas, a maioria dos trabalhos analisa a implementação de políticas em estados ou municípios brasileiros. De modo geral, foram poucos os trabalhos que discutiram as políticas educacionais no marco da União. Constatou-se, tal como Frey (2000) em relação aos estudos em políticas públicas, que as pesquisas em políticas 
educacionais concentram-se em análise ou avaliação de propostas estaduais ou municipais direcionadas a redes específicas de ensino.

No artigo "A produção do conhecimento sobre a política educacional no Brasil: um olhar a partir da Anped", Azevedo e Aguiar (2001b), analisando os trabalhos do GT05 no período de 1993 a 2000, também observaram que, apesar da subtemática "Estudos sobre políticas e programas governamentais" ser a que mais congregou trabalhos no período estudado, poucas produções abordavam políticas educacionais específicas e estabelecidas em nível nacional.

Neste agrupamento, há estudos que investigam a política educacional definida em nível do poder central, em conjunturas distintas, e que produziram contribuições significativas para a área, no que se refere à minuciosa análise documental contextualizada, pondo à disposição do campo uma competente sistematização dos processos de decisão, mas são poucos. Também são poucos os que se voltam para a análise de políticas nacionais específicas. (AZEVEDO; AGUIAR, 2001b, p. 61)

Além dos quatro temas mais frequentados no GT - "Gestão da educação e descentralização" (56 trabalhos); "Estado e reformas educacionais" (27 trabalhos); "Planejamento, avaliação e qualidade da educação" (21 trabalhos); e "Financiamento e controle social" (20 trabalhos) -, o tema "Estado, direito à educação e terceiro setor" galgou um lugar de destaque, com $8 \%$ das comunicações; contudo, poucos discutiram a relação do Estado com o terceiro setor na realização do direito à educação. A categorização dos trabalhos segundo suas características de conteúdo e o posterior reagrupamento interno evidenciou que ainda há poucos estudos sobre a inserção das organizações não governamentais (ONGs) nas políticas educacionais.

Entre os temas menos explorados no GT situou-se "Formação de professores, carreira e remuneração docente", com destaque para a questão da carreira e da renumeração. Esse fato pode ser justificado pela presença, na Anped, de um GT específico para o tratamento da questão da formação de professores, cuja produção não se constitui em objeto de estudo deste trabalho. No entanto, dada a forte presença do tema tanto na academia como fora dela, sobretudo a partir da Lei de Diretrizes e Bases da Educação Nacional (LDB), que estabeleceu novos marcos regulatórios para o exercício da docência e a profissionalização, causa estranheza a pouca presença do tema no GT. A importância da formação de novos profissionais para atender à demanda da ampliação do acesso à educação em todos os níveis e o papel da remuneração e da carreira na escolha de uma profissão pelos egressos do ensino médio de por si salientam a necessidade de avançar nos estudos e pesquisas sobre essa temática, inclusive com o objetivo de dialogar com os governos na perspectiva de modificar as condições de trabalho docente nos quesitos carreira e salário.

Chama a atenção, ainda, o pequeno número de trabalhos com os temas "Educação permanente e educação superior", "Ensino médio e profissional" e "Políticas afirmativas e cotas". Isto indica que questões de ordem social com forte presença na mídia e em diversos espaços sociais, a exemplo das políticas afirmativas, foram praticamente ausentes na produção do GT05 no período. Em 11 reuniões da Anped foram identificadas apenas duas comunicações que pautaram políticas afirmativas, ambas tratando da educação escolar indígena nos anos 2002 e 2005. Nada se publicou sobre cotas na universidade, tampouco sobre negros, ciganos e outras etnias ou grupos marginalizados dentro da sociedade brasileira ou fora dela. Possivelmente trabalhos sobre essas temáticas estão sendo 
encaminhados para os GTs Políticas de Educação Superior, Trabalho e Educação e Educação e Relações Étnico-Raciais, respectivamente. Porém, isto merece ser verificado de perto.

Quanto à tematização da produção na área de Políticas Educacionais, nota-se também uma presença ainda tênue de estudos com tal enfoque. Apesar da vasta bibliografia (AZEVEDO, 1997; AZEVEDO; AGUIAR, 2001a, 2001b; MELO, 1999; SOUZA 2003a, 2003b; entre outros) identificando lacunas de ordem teórico-metodológica na produção em políticas públicas, inclusive em educação, apenas oito trabalhos aprovados no GT05 enveredaram por esse curso. Nesse grupo situamos as comunicações que trouxeram estados do conhecimento, inclusive sobre temas específicos como o Estado e sua atuação, administração da educação, além dos trabalhos que problematizaram a produção acadêmica em política educacional propriamente. A seguir, os textos dessa categoria.

\section{0 estado do conhecimento em política educacional no interior do GT05}

No ano 2000, a comunicação intitulada "Mapeamento das possibilidades de investigação da política educacional gestada na América Latina" (KRAWCZYK; ROSAR, 2000) trouxe para o GT um balanço da produção no marco da reforma do Estado, convidando ao aprofundamento de estudos sobre as peculiaridades, continuidades e descontinuidades dos processos e conteúdos de reformas concebidas e reformas efetivadas nos países da região. Sugere-se a realização de estudos comparados com vistas ao enriquecimento das categorias de análise empregadas em políticas educacionais. No marco teórico-metodológico, as autoras desse trabalho preconizam "que se ultrapasse a tendência dos escritos pós-modernos e pós-estruturalistas em que se ampliaram os silêncios sobre as relações entre a globalização e a política global encetada pelos países hegemônicos em direção à periferia" (KRAWCZYK; ROSAR, 2000, p. 9).

Em 2003, comunicação apresentada por Maia, Ribeiro e Machado trouxe para a ordem do dia análise sobre a constituição da Administração da Educação como um campo de saber, com o objetivo de resgatar a evolução teórica da administração da educação no Brasil. Recuando no tempo, o texto analisou a produção de autores selecionados que, no período de 1950 e 1980, inscreveram suas obras como parte de uma bibliografia paradigmática em Administração Escolar, a saber: Anísio Teixeira, Quirino Ribeiro, Lourenço Filho, Myrtes Alonso, Vitor Henrique Paro e Maria de Fátima Costa Félix. Após apresentação sintética das obras selecionadas desses autores, o estudo conclui que "é necessário o resgate desse material e de outros a fim de que se possa visualizar o conjunto dessa teoria com suas diferentes fontes de inspiração e suas implicações específicas" (MAIA; RIBEIRO; MACHADO, 2003, p. 17). O texto trouxe contribuição ao debate sobre o tema focado, recuperando, inclusive, o lugar da Anpae nesse processo, mas não fez referência direta à construção da área de Política Educacional.

Gonçalves (2004) também se ocupou de tema específico na área de Políticas Educacionais, com enfoque na relação Estado-educação, em análises sobre políticas da educação básica, tomando como objeto de estudo periódicos e anais de eventos selecionados nas áreas de Educação, História, Ciências Sociais, Administração e Economia. A comunicação é um recorte de uma pesquisa mais ampla por meio da qual a autora evidencia diferentes dimensões das produções no eixo Estado-educação básica, assim como a predominância de estudos com esse enfoque nos periódicos e eventos da área 
de Educação. Entre as conclusões apresentadas, ressaltou a tendência à repetição das ideias e à fragmentação da produção quanto aos temas e perspectivas. Defendeu, por fim, a intensificação da organização e coordenação das pesquisas nesse eixo, reconhecendo o protagonismo tanto da Anped quanto da Anpae.

Maia e Machado (2006) voltaram ao tema da trajetória do conhecimento em Administração da Educação, desta feita perquirindo publicações da Anpae. O objetivo da pesquisa foi identificar as características e as contribuições da produção teórica da entidade. As autoras analisaram os quatro primeiros textos dos Cadernos de Administração Escolar (1961-1968) e os textos publicados na Revista Brasileira de Política e Administração da Educação (RBPAE) no período de 1983 a 2000, nas categorias: Administração, Gestão e Profissionais da Educação, de acordo com classificação realizada por elas. Entre as conclusões, indicaram que as publicações da Anpae apresentam postura crítica em relação aos temas analisados e resistência à aceitação de atos e práticas antidemocráticos. Ainda em relação à construção de uma base teórico-metodológica, defenderam a ideia de que:

[...] o grande mérito da trajetória do conhecimento esteve no abandono da necessidade de se formular uma teoria generalizável de Administração da educação e na adoção de uma postura flexível, que contempla a diversidade de realidades presentes em nosso contexto social e educacional. (MAIA; MACHADO, 2006, p. 14)

Em 2007, as mesmas autoras retornaram ao GT com a comunicação "Ensaio para a construção de uma terminologia em Administração da Educação no Brasil: fazendo conversar os conceitos" (MAIA; MACHADO, 2007). Nesse trabalho, buscavam aprofundar o conhecimento da constituição teórica da área de Administração da Educação, tendo como referência obras consideradas paradigmáticas, além de uma caracterização da área por meio da construção de "verbetes explicativos, constituindo um glossário dos termos usuais" (MAIA; MACHADO, 2007, p. 1). Partindo da constatação da existência de expressões que diferem entre si, mas possuem conceitos quase idênticos, a ideia de "fazer conversar os conceitos" intencionou melhorar a compreensão dos fenômenos educacionais e administrativos, principalmente no âmbito da escola. $O$ trabalho sugere que a multiplicidade de conceitos naquelas circunstâncias acentua "a distância que separa a teoria educacional da prática efetiva, pois acaba por se tornar num enredado multirreferencial, cuja complexidade é de difícil apreensão" (MAIA; MACHADO, 2007, p. 15).

Ainda sobre o tema políticas educacionais, no texto "Conhecimento e interesse: fatores que influenciam a escolha dos objetos de pesquisa no campo acadêmico da pesquisa sobre política educacional", Santos (2008) analisa o envolvimento de 14 pesquisadores vinculados a programas de pós-graduação do Nordeste do país, com seus respectivos objetos de estudo, tendo como referência a teoria de campo de Bourdieu e a análise de discurso textualmente orientada (ADTO) desenvolvida por Fairclough. Num esforço para construir uma compreensão acerca do interesse dos pesquisadores em objetos de estudo relativos à política educacional, o trabalho mostra que "o par dialético 'conhecimento e interesse' está marcado por circunstâncias e fatores que vinculam o pesquisador às possibilidades de produzir um discurso que possibilite um aumento do seu capital científico, e, por conseguinte, do seu capital social”' (SANTOS, 2008, p. 17). 
Esta mesma autora publicou posteriormente, em co-autoria com Janete Azevedo, o artigo "A pós-graduação no Brasil, a pesquisa em educação e os estudos sobre a política educacional: os contornos da constituição de um campo acadêmico" (SANTOS; AZEVEDO, 2009) e, no âmbito do GT05, a comunicação "A ação de pesquisadores que investigam a política educacional: analisando estratégias de delimitação do campo acadêmico no contexto de produção do discurso" (SANTOS; AZEVEDO, 2010), indicando não só a formação de novas parcerias de trabalho, mas, principalmente, a continuidade de estudos nesse agrupamento. Por meio dessas produções, analisaram a conformação da pesquisa em políticas educacionais nos programas de pós-graduação em Educação situados na Região Nordeste do Brasil e que mantêm linha de pesquisa em Política Educacional. Ao perscrutarem pesquisadores que atuam em política educacional, observaram não só a importância que vem adquirindo essa área temática, mas um processo de consolidação desta, marcado por disputas pela aquisição de autoridade científica.

A partir da análise do discurso, as autoras puderam constatar que os pesquisadores usam estratégias tanto de concorrência e competição como de cooperação para a consolidação do campo de pesquisa. Observaram, também, a coexistência de abordagens teórico-metodológicas diferentes num mesmo programa de pós-graduação, com a convivência pacífica em alguns casos e conflituosa em outros. As autoras concluíram que a homogeneidade ou a heterogeneidade teórico-metodológica não determinam por si só o fortalecimento ou a fragilidade de um campo. A existência de pesquisadores que buscam a consolidação de novas abordagens teórico-metodológicas é compreendida por Santos e Azevedo (2010, p. 5) como "uma estratégia de investimento cujos resultados positivos vão se expressar no reconhecimento da autoridade daquele pesquisador nessa área específica".

Embora tenham entrevistado pesquisadores que assinalaram a realização de pesquisas interinstitucionais, as autoras consideraram que há pouco intercâmbio entre os pesquisadores dos programas de pós-graduação do Nordeste, o que dificulta o fortalecimento da região no cenário nacional. As descobertas anunciadas no estudo se encaminham para reforçar a interpretação de que a afinidade teórico-metodológica é um importante fator para a aproximação dos pesquisadores das políticas educacionais e o fortalecimento da produção na área. Apesar disso, a realização de pesquisas coletivas ainda figura como um obstáculo aos pesquisadores.

Olhando para o conjunto dos trabalhos apresentados no GT05 na última década, é notável o empenho na construção de uma ampla revisão das produções nos temas específicos, agregando análises e indicações para novos estudos em políticas educacionais. Perduram, contudo, a abundância de estudos setoriais e a tendência às abordagens teóricometodológicas difusas.

A ampliação dos debates sobre abordagens teórico-metodológicas em políticas públicas, nesse contexto, apresenta-se como um grande desafio para a verticalização da produção, uma vez que, como alerta Charlot (2006, p. 10), a educação "é uma disciplina epistemologicamente fraca: mal definida, de fronteiras tênues, de conceitos fluidos", que necessita urgentemente definir conceitos próprios e métodos de pesquisa específicos. Nomeadamente em políticas públicas, o debate sobre as contribuições teóricometodológicas mais correntes e a problematização da ênfase no papel da sociedade política, incluindo a própria noção de Estado stricto sensu, apresentam-se como questões fulcrais na consolidação da área.

Neste sentido, cabe destacar a ampliação das análises sobre políticas públicas a partir da noção de Estado integral, dado que esta opção teórico-metodológica não só questiona as formulações que enfatizam o protagonismo do governo para a resolução de 
problemas, mas propõe a ampliação de debates sobre a constituição do campo, sem negar a natureza política que todo estudo na área encerra.

\section{Estado e política educacional: sentidos e implicações analíticas}

Entre as várias definições correntes de política pública, Souza (2003b) recupera algumas que ilustram a diversidade de acepções que envolvem essa expressão:

Mead [...] a define como um campo dentro do estudo da política que analisa o governo à luz de grandes questões públicas. Lynn [...] a define como um conjunto específico de ações do governo que irão produzir efeitos específicos. Peters [...] segue o mesmo veio: política pública é a soma das atividades dos governos, que agem diretamente ou através de delegação, e que influenciam a vida dos cidadãos. Dye [...] sintetiza a definição de política pública como "o que o governo escolhe fazer ou não fazer". A definição mais conhecida continua sendo a de Laswell [...], ou seja, decisões e análises sobre política pública implicam responder às seguintes questões: quem ganha o quê, por quê e que diferença faz. (SOUZA, 2003b, p. 12)

Ainda de acordo com Souza (2003b), entre as perspectivas mais correntes as políticas públicas referem-se ao

Campo de conhecimento que busca, ao mesmo tempo, "colocar o governo em ação" e/ou analisar essa ação (variável independente) e, quando necessário, propor mudanças no rumo ou curso dessas ações e/ou entender por que e como as ações tomaram certo rumo em lugar de outro (variável dependente). (SOUZA, 2003b, p. 13)

É visível nessas formulações uma visão de Estado restrita aos agentes políticos, particularmente os governos, situados como protagonistas para a resolução de problemas.

Produções com maior fluxo na área de Educação, por sua vez, vêm sendo polarizadas pelas abordagens "estadocentrista" e "anti-estadocentrista", como podemos notar nas análises de Power (2011) ou ainda em Ball (2011a, 2011b), ao problematizar o racionalismo instrumental da década de 1990 e advogar a visão pós-epistemológica. Diz este último autor:

No lugar de normas e discursos pregressos e rígidos, devemos, como Richard Rorty sugere, estabelecer um campo em que se joga com as ideias e se exploram ironias radicais. Na visão pós-epistemológica de Rorty, a construção de diálogos, mais do que esforços epistemológicos criadores da verdade, deve ser a matéria-prima das ciências pósestruturais. (BALL, 2011b, p. 96)

No cerne desse debate repousa a disputa dos "modelos analíticos" e suas orientações teóricas. Os pesquisadores brasileiros da área de Educação também não fogem a isso, embora, como tendência, os estudos de natureza epistemológica não se constituam em focos principais de estudo e as noções de política educacional apareçam subliminarmente nos textos. Mesmo como subtexto, a associação entre política educacional e Estado tem trazido forte marca ritualística em que paira uma suposta gênese universal do 
Estado, isto é, o silenciamento em torno da questão deixa escapar a explicitação dos seus sentidos diversos. Mormente insinua-se o Estado como o lugar principal da política e, movimento contínuo, o protagonismo do governo como sua expressão. Essa tendência acaba por abrandar o papel de outros atores sociais na formulação e implementação das políticas, assim como as contradições dos processos político-sociais que lhes dão moldura e conteúdo.

Ao supor o Estado universal, principalmente pela omissão dos seus sentidos, as análises se supõem menos "estadocentricas" e mais representativas dos paradigmas avessos às abordagens críticas, por supô-las limitadas ao insistirem na tradição dos estudos que buscam explorar relações entre aspectos estruturais e específicos dos temas de estudo.

Em direção oposta a esse esforço para "desideologizar" a política, avocamos a natureza contraditória das políticas públicas em sua dupla e simultânea natureza de vetor potencial de mobilização de agentes sociais para a defesa de seus interesses e elemento de contenção dos agentes, conforme sua posição nas estruturas e as correlações entre os campos de força. Neste sentido, as políticas públicas constituem-se em movimentos complexos que arregimentam esforços de diferentes agentes para dar corpo a séries de ações e comportamentos que produzem repercussões na vida social. Tal compreensão busca, simultaneamente, destacar o Estado além do aparelho do governo e as políticas públicas como movimentos multilaterais de proposições e decisões coletivas que disputam as agendas de Estado e sua hegemonia.

Gramsci (2000) ressalta no Estado as funções de justificar e manter a dominação conciliando força e consenso ativo dos governados, isto é, hegemonia. Sua concepção de Estado supõe a diferenciação entre o Estado em sentido estrito e o Estado em sentido amplo ou integral. Tal diferenciação não implica dois conceitos de Estado, mas dois momentos da articulação do campo estatal.

Em um sentido estreito, o Estado se identifica com o governo, com o aparelho de ditadura de classe, na medida em que ele possui funções coercitivas e econômicas. A dominação de classe se exerce através do aparelho de Estado no sentido clássico (exército, polícia, administração, burocracia). Mas essa função coercitiva é inseparável de um certo papel adaptativo-educativo do Estado, que procura realizar uma adequação entre aparelho produtivo e moralidade das massas populares. (BUCIGLUCKSMANN, 1980, p. 127, grifo da autora)

Olhando para as definições correntes de políticas públicas e a ênfase na sociedade política ou no Estado estrito nelas presente, questiona-se a separação da sociedade civil em relação à sociedade política e se propõe a ampliação das análises sobre políticas públicas a partir da noção de Estado integral. Isto traz para o centro das análises a diversidade de atores, as disputas e tensões presentes na elaboração e configuração das políticas públicas. Neste marco entende-se que as políticas públicas são elaboradas em movimentos de correlação de força em que atuam tanto a sociedade política quanto a sociedade civil e não necessariamente como instâncias que se opõem, mas antes representam projetos de sociedade em disputa. Não se trata, portanto, de movimentos consensuais, nem unilaterais, mas de formas de intervenção das múltiplas sociedades particulares, de caráter duplo, de que fala Gramsci (2000).

\section{Considerações finais}


As políticas educacionais são definidas, implementadas e reformuladas dentro de um processo dinâmico, em que conceitos, modelos e interpretações da realidade não são permanentes, são gerados em outras áreas e transitam para a educação, e vice-versa, assim como observa Charlot (2006, p. 3) em relação ao campo de pesquisa em educação. Para o autor, a educação

[...] é um campo de saber fundamentalmente mestiço, em que se cruzam, se interpelam e, por vezes, se fecundam, de um lado, conhecimentos, conceitos e métodos originários de campos disciplinares múltiplos, e, de outro lado, saberes, práticas, fins éticos e políticos. O que define a especificidade da disciplina é essa mestiçagem, essa circulação.

Ao observar essa dinâmica na década de 2000, constata-se que os estudos sobre as reformas educacionais tiveram destaque, tendo como ênfases mais recorrentes os condicionantes das reformas em seus aspectos econômicos, políticos e sociais, as mudanças introduzidas nas concepções pedagógicas, na organização dos sistemas, assim como as tendências na gestão da educação pública frente aos rumos na gestão do Estado (inclui-se aí os temas da avaliação e do financiamento).

Deriva desse processo uma ampla variedade temática, a qual privilegia, em sua maior parte, aspectos relativos às políticas educacionais de âmbito local, embora essa limitação já tenha sido apontada por Azevedo e Aguiar (2001a, p. 86):

[...] a heterogeneidade da produção tende a impossibilitar uma acumulação de conhecimentos que venha a expressar a presença de "um programa de pesquisa", a partir do qual a comunidade concernente, em estreita interação, possa desenvolver e aprimorar procedimentos teóricometodológicos com maior grau de consistência e com melhor grau de delimitação.

Tais autoras consideraram que essa heterogeneidade, ao mesmo tempo em que evidencia a abertura para os mais distintos temas e problemas relacionados às políticas públicas de Educação, implicam restrições no que se refere ao fortalecimento teórico da área. Reforçando essa discussão, Barretto (2009) aponta para a escassez de trabalhos que procuram relacionar resultados e políticas de âmbito geral. "O mais comum é que a abordagem, seja ela no âmbito federal, estadual ou local, ocupe-se de grande variedade de objetos, sendo ainda tênue o esforço cumulativo capaz de adensar as temáticas exploradas" (BARRETTO, 2009, p. 3).

A busca pela consolidação de uma área de saber inscreve-se, nesse contexto, como uma questão estratégica para ultrapassar a fase da institucionalização, localizada no processo da abertura política brasileira, e de rompimento com a trajetória europeia referida por Melo (1999), e que aproximaram a análise de políticas públicas a agendas e interesses de entidades governamentais.

Essa perspectiva, quando confrontada aos dados coletados na pesquisa aqui apresentada, mostra-se ainda tênue, dadas as evidências de que as características da produção que teve trânsito no GT05 da Anped entre 2000 e 2010 pouco se diferenciou das características observadas em estudos pregressos. Isto sinaliza, por um lado, que há obstáculos a serem superados no próprio modo da área organizar sua produção e, por outro, que os diagnósticos sobre os processos de institucionalização da área, suas lacunas e desafios ainda são assumidos parcialmente, muito mais a partir de iniciativas individuais 
do que como expressão de trabalhos em grupos organizados. Conforme foi demonstrado, de oito comunicações que procuraram analisar as produções na área ou temáticas específicas sobre abordagens teórico-metodológicas, três foram originadas em um só grupo de pesquisa. Aliada a isto, a produção individual apresenta-se como um dado expressivo, uma vez que a maioria dos trabalhos foi produto de um só pesquisador.

Considerando o conjunto das 203 comunicações aprovadas no GT no período, a ausência de produções em rede também é fato. Dado o desafio de avançar na verticalização das pesquisas e na constituição de pressupostos teórico-metodológicos que deem conformidade às pesquisas em políticas públicas, com atenção às políticas educacionais, a construção de redes de pesquisa coloca-se como imperativo para o avanço na superação dos desafios e limites apresentados tanto nas referências bibliográficas quanto nos dados desta pesquisa.

A abundância de estudos setoriais em detrimento de análises mais específicas, porém articuladas, pode ser decorrência, em parte, da pouca tradição de produções coletivas. Todavia, são menores as possibilidades de um único pesquisador, na maioria das vezes sem financiamento, empreender pesquisas de caráter mais abrangente e ao mesmo tempo mais adensadas.

A esse respeito, Barretto (2009) pondera que grande parte dos trabalhos apresentados na Anped provém de dissertações de mestrado e teses de doutorado, as quais, diante do escasso financiamento, aliado à fragilidade de inserção dessas pesquisas em projetos de mais largo escopo, acaba por resultar na multiplicação de "estudos de caso". Para a autora:

\begin{abstract}
Embora os estudos que costumam ser realizados possam contribuir para elucidar aspectos das políticas educacionais, a preferência pelas abordagens microssociais tem contribuído para diluir a atenção de questões relativas ao seu desenho institucional, cobertura e financiamento, cruciais para entender os condicionantes, o modo como funcionam e os resultados a que chegam. Além disso, nunca é demais lembrar que as pesquisas qualitativas exigem grande acuidade e experiência dos investigadores e que os nossos pesquisadores são, na maioria, aprendizes nesse domínio. (BARRETTO, 2009, p. 2)
\end{abstract}

Isto se agrava quando se consideram os tempos das pesquisas em tão ingrata era de cobranças por produção acadêmica em série, sobretudo na pós-graduação. Contornar esses obstáculos, pois, não é tarefa individual e certamente o GT Estado e Política Educacional tem muito a contribuir com essa agenda.

\title{
Referências
}

AZEVEDO, J. M. L. de. A educação como política pública. Campinas, SP: Autores Associados, 1997.

AZEVEDO, J. M. L. de; AGUIAR, M. A. da S. Políticas de educação: concepções e programas. In: WITTMANN, Lauro C.; GRACINDO, R. V. (Coord.). O estado da arte em política e gestão da educação no Brasil (1991-1997). Brasília: Anpae; Campinas, SP: Autores Associados, 2001a. p. 71-87. 
AZEVEDO, J. M. L. de; AGUIAR, M. A. da S. A produção do conhecimento sobre política educacional no Brasil: um olhar a partir da Anped. Educação \& Sociedade, Campinas, ano XII, n. 77, p. 49-70, dez. 2001b.

BALL, S. J. Intelectuais ou técnicos? O papel indispensável da teoria nos estudos educacionais. In: BALL, S. J.; MAINARDES, J. (Org.). Políticas educacionais: questões e dilemas. São Paulo: Cortez, 2011a. p. 78-99.

BALL, S. J. Sociologia das políticas educacionais e pesquisa crítico-social: uma revisão pessoal das políticas educacionais e da pesquisa em política educacional. In: BALL, S. J.; MAINARDES, J. (Org.). Políticas educacionais: questões e dilemas. São Paulo: Cortez, 2011b, p. 21-53.

BARRETTO, E. S. de S. Perspectivas teóricas e metodológicas da pesquisa em política educacional na atualidade. Estudos em Avaliação Educacional,São Paulo, n. 44, p. 493 507, nov. 2009.

BARDIN, L. Análise de conteúdo. Lisboa: Edições 70, 2004.

BOURDIEU, P. Razões práticas: sobre a teoria da ação. 10. ed. Campinas, SP: Papirus, 2010.

BUCI-GLUCKSMANN, C. Gramsci e o Estado. 2. ed. Rio de Janeiro: Paz e Terra, 1980.

CADERNO CRH, Salvador: CRH/Ufba, v. 16, n. 39, jul./dez. 2003.

COORDENAÇÃO DE APERFEIÇOAMENTO DE PESSOAL DE NÍVEL SUPERIOR. Planilhas comparativas de avaliação trienal/Capes/2010. Brasília, DF, 2010.

CHARLOT, B. A pesquisa educacional entre conhecimentos, políticas e práticas: especificidades e desafios de uma área de saber. Revista Brasileira de Educação, Rio de Janeiro, v. 11, n. 31, p. 7-18, jan./abr. 2006.

FIGUEIREDO, M. F.; FIGUEIREDO, A. M. C. Avaliação política e avaliação de políticas: um quadro de referência teórica. Análise \& Conjuntura, Belo Horizonte, v. 1, n. 3, p. 107-127, set./dez. 1996.

FREY, K. Políticas públicas: um debate conceitual e reflexões referentes à prática da análise de políticas públicas no Brasil. Planejamento e Políticas Públicas, Brasília, DF, n. 21, p. 211-259, jun. 2000.

GONÇALVES, N. G. A produção acadêmica brasileira sobre a relação Estado e educação (1971-2000): temas, críticas e expectativas. In: REUNIÃO ANUAL DA ANPED, 27., 2124 nov. 2004, Caxambu, MG. Anais... Rio de Janeiro: Anped, 2004. Disponível em: <http://27reuniao.anped.org.br/?_ga=1.27112701.1936825704.1427765489>. Acesso em: 27 mar. 2016.

GRAMSCI, A. Cadernos do cárcere. v. 3: Maquiavel: notas sobre o Estado e a política. Edição e tradução Carlos Nelson Coutinho. Co-edição Luiz Sérgio Henriques e Marco Aurélio Nogueira. Rio de Janeiro: Civilização Brasileira, 2000.

KRAWCZYK, N. R.; ROSAR, M. F. F. Mapeamento das possibilidades de investigação da política educacional gestada na América Latina. In: REUNIÃO ANUAL DA ANPED, 23., 24-28 set. 2000, Caxambu, MG. Anais... Rio de Janeiro: Anped, 2000. Disponível em: <http://23reuniao.anped.org.br/trabtit1.htm\#gt5>. Acesso em: 12 jan. 2010. 
MAIA, G. Z. A.; MACHADO, L. M. Ensaio para a construção de uma terminologia em Administração da Educação no Brasil: fazendo conversar os conceitos. In: REUNIÃO ANUAL DA ANPED, 30., 7-10 out 2007, Caxambu, MG. Anais... Rio de Janeiro: Anped, 2007. Disponível em: <http://30reuniao.anped.org.br/?_ga=1.1560817.1936825704.1427765489>. Acesso em: 27 mar. 2016.

MAIA, G. Z. A.; MACHADO, L. M. As publicações da Anpae e a trajetória do conhecimento em administração da educação no Brasil. In: REUNIÃO ANUAL DA ANPED, 29., 15-18 out. 2006, Caxambu, MG. Anais... Rio de Janeiro: Anped, 2006. Disponível em: <http://29reuniao.anped.org.br/?_ga=1.40327650.1936825704.1427765489>. Acesso em: 27 mar. 2016.

MAIA, G. Z. A.; RIBEIRO, D. S.; MACHADO, L. M. A evolução do conhecimento em administração da educação no Brasil: suas raízes e processos de constituição teórica. In: REUNIÃO ANUAL DA ANPED, 26., 5-8 out. 2003, Poços de Caldas. Anais... Rio de Janeiro: Anped, 2003. Disponível em: <http://www.anped.org.br/reunioes/26/textos>. Acesso em: 12 jan. 2010.

MELO, M. A. Estado, governo e políticas públicas. In: MICELI, S. (Org.). O que ler na ciência social brasileira (1970-1995). 2. ed. São Paulo: Sumaré: Anpocs; Brasília, DF: Capes, 1999. p. 59-99.

POWER, S. O detalhe e o macrocontexto: o uso da teoria centrada no Estado para explicar práticas e políticas educacionais. In: BALL, S. J.; MAINARDES, J. (Org.). Políticas educacionais: questões e dilemas. São Paulo: Cortez, 2011. p. 54-77.

RAMALHO, B. L.; MADEIRA, V. de P. C. A pós-graduação em Educação no Norte e Nordeste: desafios, avanços e perspectivas. Revista Brasileira de Educação, Rio de Janeiro, n. 30, p. 70-81, set./dez. 2005.

REVISTA BRASILEIRA DE CIÊNCIAS SOCIAIS. São Paulo: Anpocs, v. 18, n. 51, fev. 2003. Disponível em: <http://www.scielo.br/scielo.php?script=sci_issuetoc\&pid=0102690920030001\&lng=en\&nrm=iso >. Acesso em: 28 mar. 2016.

SANDER, B. Administração da educação: genealogia do conhecimento. Brasília, DF: Liber Livro, 2007.

SANTOS, A. L. F dos. Conhecimento e interesse: fatores que influenciam a escolha dos objetos de pesquisa no campo acadêmico da pesquisa sobre política educacional. In: REUNIÃO ANUAL DA ANPED, 31., 19-22 out. 2008, Caxambu, MG. Anais... Rio de Janeiro: $\quad 2008 . \quad$ Anped, Disponível em: <http://31reuniao.anped.org.br/1trabalho/trabalho05.htm. Acesso em: 27 mar. 2016.

SANTOS, A. L. F. dos; AZEVEDO, J. M. L. de. A ação de pesquisadores que investigam a política educacional: analisando estratégias de delimitação do campo acadêmico no contexto de produção do discurso. In: REUNIÃO ANUAL DA ANPED, 33., 17-20 out. 2010, Caxambu, MG. Anais... Rio de Janeiro: Anped, 2010. Disponível em: <http://33reuniao.anped.org.br/internas/ver/trabalhos-gt05>. Acesso em: 12 jan. 2011.

SANTOS, A. L. F. dos; AZEVEDO, J. M. L. de. A pós-graduação no Brasil, a pesquisa em educação e os estudos sobre a política educacional: os contornos da constituição de um 
campo acadêmico. Revista Brasileira de Educação, Rio de Janeiro, n. 30, p. 534-550, set./dez. 2009.

SOUZA, C. "Estado do campo" da pesquisa em políticas públicas no Brasil. Revista Brasileira de Ciências Sociais, São Paulo, v. 18, n. 51, p. 15-20, fev. 2003a.

SOUZA, C. Introdução: políticas públicas; questões temáticas e de pesquisa. Caderno CRH, Salvador, n. 39, p. 11-24, jul./dez. 2003b.

SOUZA, D. B; FARIA, L. C. M. de. Política, gestão e financiamento de sistemas municipais públicos de educação no Brasil: bibliografia analítica (1996-2002). São Paulo: Xamã; Niterói: Intertexto, 2005.

WITTMANN, L. C.; GRACINDO, R. V. (Coord.) O estado da arte em política e gestão da educação no Brasil (1991-1997). Brasília, DF: Anpae; Campinas, SP: Autores Associados, 2001.

\section{Notas}

${ }^{1}$ Versão preliminar deste artigo foi apresentada na $33^{\text {a }}$ Reunião Anual da Associação Nacional de PósGraduação e Pesquisa em Educação (Anped).

${ }^{2}$ Professora titular da Universidade Estadual de Feira de Santana (Uefs), atuando na área de Políticas Educacionais, tanto nos cursos de licenciatura quanto na pós-graduação em Educação, com ênfase em História das Políticas Educacionais, Gestão e Estudos Epistemológicos em Políticas Educacionais. Contato: <antoniasilv@gmail.com>.

${ }^{3}$ Professora adjunta da Universidade Federal da Grande Dourados (UFGD), atua na área de Política e Gestão Educacional, com ênfase em Planejamento da Educação. Contato: <elisangelascaff@ufgd.edu.br>.

4 Professora de graduação e pós-graduação da Escola de Filosofia, Letras e Ciências Humanas da Universidade Federal de São Paulo (Unifesp). Desenvolve pesquisas em Políticas Públicas para a Educação e Gestão Educacional, com destaque para estudos sobre a produção acadêmica em políticas educacionais. Contato:<marciajacomini@uol.com.br>.

${ }^{5}$ É importante esclarecer que trabalhos assinados por autores de instituições diferentes tiveram computadas todas as instituições e, quando foi o caso, todas as agências de fomento implicadas.

Recebido: fevereiro-16 Aprovado: março-16 